\title{
PENGARUH ACARA FESTIVAL SENI TERHADAP CITRA SEKOLAH DI SMA NEGERI 6 PEKANBARU
}

\author{
Idawati \\ Fakultas Ilmu Komunikasi Universitas Islam Riau \\ Email: idawatiuir@comm.uir.ac.id
}

\begin{abstract}
Abstrak
Makin berkembangnya jumlah SMAN diKota Bertuah, tentulah Sekolah - sekolah ini masing-masing ingin meningkatkan kualitas melalui Pencitraan. Dan program Sekolah juga merupakan salah satu bentuk citra Sekolah tersebut, dengan berbagai cara dan versi yang berbeda dari masing-masing sekolah untuk meningkatkan citranya agar dekat dengan hati masyarakat terutama calon peserta didik. Demikian juga, dengan SMAN 6 Pekanbaru yang selalu ingin meningkatkat Citranya berbagai cara dan upaya yang dilakukan oleh SMAN 6, salah satunya dengan meningkatkan Acara festival seni yang merupakan salah satu program kerja sekolah.Teknik pengumpulan data dalam penelitian ini yaitu: kuesioner, wawacara, dokumentasi, studi pustaka. Dalam penelitian ini, peneliti menggunakan skala pengukuran adalah skala likert (liket scale) yang digunakan untuk mengukur sikap, pendapat, persepsi, seseorang tentang suatu kejadian atau gejala sosial. Teknik analisa data dalam penelitian ini yaitu: menggunakan teknik analisis data regresi sederhana. Pengaruh acara festival seni terhadp citra SMAN 6 sangat berpengaruh signifikan hal ini dibuktikan dari hasil regresi linier sederhana.
\end{abstract}

Kata Kunci: Festival Seni, Citra Sekolah.

\begin{abstract}
The growing number of SMAN in the Sorcerer City, of course these Schools each want to improve quality through Imaging. And the School program is also one form of the School's image, in various ways and different versions of each school to improve its quality so that it is close to the hearts of the community especially prospective students.Likewise, with SMAN 6 Pekanbaru who always wants to improve the image of various ways and efforts made by SMAN 6, one of them is by increasing the Art Festival program which is one of the school's work programs. Data collection techniques in this study are: questionnaire, interview, documentation, study library.In this study, researchers using a scale of measurement is a Likert scale (scale scales) used to measure attitudes, opinions, perceptions, someone about a social event or phenomenon. Data analysis techniques in this study are: using simple regression data analysis tecThe influence of the art festival program on the image of SMAN 6 has a very significant effect, as evidenced by the results of simple linear regression.
\end{abstract}

Keywords: Festival Of The Arts, The Image Of The School

\section{PENDAHULUAN}

Semakin berkembangnya jumlah SMA di Kota Pekanbaru sudah tentu masing-masing saling bersaing mempertahankan kualitasNya untuk menjadi yang terbaik dan terdepan 
dimata publik. Persaingan ini dimanfaatkan oleh sekolah-sekolah dalam merekrut calon peserta didik baru dengan berbagai cara tertentu seperti, meningkatkan kualitas citra sekolah, merevisi kurikulum baru, merubah penampilan -penampilan baru gaya yang bersaing dengan sekolah yang ternama. Masing-masing SMA dengan berbagai gaya serta cara khusus untuk membentuk citra Sekolah.

Upaya inilah yang dilakukan oleh SMA Negeri 6 sebagai salah satu cara untuk mewujudkan pesan komunikasi bisnis kepada masyarakat, khususnya peserta didik dan calon peserta didik. Salah satu caranya harus bisa membangun citra sekolah yang baik sehingga namanya bisa melekat dihati masyarakat. Apalagi letak SMAN 6 inipun kurang strategis, yakni jauh dari keramaian, Sehingga calon peserta didik kurang tertarik untuk masuk ke SMA ini, dan kalaupun mereka harus memilih SMA ini itu merupakan jalan terakhir setelah tidak bisa diterima disekolah pavorit pilihannya wawancara penulis dengan narasumber (Hasniah, Agustus: 2012).

Berdasarkan pertimbangan inilah pihak sekolah kembali bekerja keras untuk membentuk citra yang positif.Untuk membangun sebuah citra, langkah yang harus dilakukan adalah: Menentukan kelompok sasaran citra. Kelompok sasaran adalah anggota masyarakat yang berperan penting terhadap keberhasilan usaha dan masa depan perusahaan (Wilson Arafat, 206:30).

Dengan demikian SMA Negeri 6 dalam menentukan kelompok sasaran citra yakni siswa, calon siswa (calon peserta didik). Citra sekolah yang baik tidak hanya ditentukan oleh prestasi akademik, tetapi juga ditentukan oleh berbagai prestasi yang lain salah satunya adalah prestasi dibidang seni. Untuk membangun citra positif dimata masyarakat sekolah juga harus menancapkan kunci-kunci sukses dalam mencapai keberhasilan citra, sehingga citra sekolah bukan hanya sukses dilingkungannya (intern) namun hingga ke luar lingkungan (ekstern) (Data hasil Observasi 2012). Dari latar belakang diatas penulis tertarik untuk meneliti dengan judul Pengaruh Acara festival Seni Terhadap Citra Sekolah.

\section{Ilmu Komunikasi}

Istilah komunikasi kian hari kian popular, begitu populernya hingga muncul berbagai istilah tentang ilmu komunikasi. Ada komunikasi timbal balik, ada komunikasi tatap muka, ada komunikasi langsung, komunikasi tidak langsung, komunikasi vertical, komunikasi horizontal, komunikasi dua arah dan lain sebagainya, kesemua istilah ini tidaklah perlu dipusingkan.

Sebuah defenisi singkat yang dibuat oleh Harold D. Lasswell bahwa cara yang tepat untuk menerangkan suatu tindakan komunikasi adalah menjawab pertanyaan "Siapa yang menyampaikan, apa yang disampaikan, melalui saluran apa, kepada siapa dan apa pengaruhnya"

Komunikasi adalah Proses dimana dua orang atau lebih membentuk atau melakukan pertukaran informasi dengan satu sama lainnya, yang pada gilirannya akan tiba pada pengertian yang saling mendalalam. Komunikasi adalah proses penyampaian oleh seseorang kepada orang lain untuk memberitahu atau mengubah sikap, pendapat, atau perilaku, baik langsung secara lisan maupun tidak langsung melalui media (Hubeis Musa, 2012:4). 
Pesan yang diberikan pada komunikan dapat dipengaruhi oleh sensasi yang dihasilkan mereka, jika kuat sensasi yang dimiliki dan besarnya daya tarik dari stimulus yang diterima maka secara langsung akan mempengaruhi pikiran komunikan melalui panca indera. Pikiran akan menyeleksi dari stimulus yang diterima sehingga akan menghasilkan kebutuhan, ekspektasi dan nilai-nilai. Dari aktifitas itu akan menghasilkan respon yang akan membawa perubahan pada sikap yang positif ataupun sikap negative.

Tujuan komunikasi secara sederhana, sesorang yang berkomunikasi hanya mencari anggukan kepala lawan komunikasinya, ketika lawan berbicara menganggukkan kepala sampai kepada titik inti permasalahan, maka lawan bicara kita anggap sudah memahami dari proses komunikasi yang kita lakukan (Munir Abdullah, 2012:12).

\section{Citra}

Menurut Kotler citra adalah: seperangkat keyakinan, ide, dan kesan yang dimiliki oleh seseorang terhadap suatu merek. Karena itu sikap dan tindakan konsumen terhadap suatu merek sangat ditentukan oleh citra itu sendiri. Kotler juga menambahkan bahwa citra merupakan syarat dari merek yang kuat dan citra adalah persepsi masyarakat yang relative konsisten dalam jangka panjang (enduring perception). Jadi tidak mudah untuk membentuk citra, sehingga bila terbentuk akan sulit untuk mengubahnya. Citra yang dibentuk harus jelas dan memiliki keunggulan bila dibandingkan dengan pesaingnya (Kotler, 2003: 10).

Membangun citra yang kuat tidak berbeda dari membangun sebuah rumah. Untuk memperoleh bangunan rumah yang kokoh, kita memerlukan fondasi yang kuat. Cara membangun citra adalah sebagai berikut:

1. Memiliki posisi yang tepat, merek dapat diposisikan dengan berbagai cara, misalnya dengan menempatkan posisinya secara spesifik dibenak pelanggan. Membangun posisioning adalah menempatkan semua aspek dari bran value (termasuk manfaat ungsional) secara konsisten sehingga selalu menjadi nomor satu dibenak pelanggan.

2. Memiliki brand value yang tepat. Brand value juga mencerminkan brand equty secara real sesuai dengan costumer valuesnya.

3. Memiliki konsep yang tepat. Tahap akhir yang harus dilakukan untuk membangun citra adalah memiliki konsep yang tepat dan posisi yang tepat kepada konsumen ( Freddy, 2004:5).

\section{Festival Seni}

Seni adalah salah satu unsur kebudayaan yang tumbuh dan berkembang sejajar dengan perkembangan manusia selaku penggubah dan penikmat seni. Seni memiliki nilai estetis (indah) yang disukai oleh manusia dan mengandung ide-ide yang dinyatakan dalam bentuk aktivitas atau rupa sebagai lambang.

Apresiasi seni adalah kesanggupan untuk menerima dan memberikan penghargaan terhadap karya seni. Proses apresiasi terjadi saat pengamat berkomunikasi dengan karya seni. Maka untuk membina dan mengembangkan apresiasi harus sering berkomunikasi dengan karya seni, misalnya melalui kegiatan pertunjukkan seni atau pementasan seni. Dalam hal ini yang dipentaskan oleh SMAN 6 adalah sesuai dengan kebudayaan dan cirikhas mereka yaitu seni 
musik. Seni music meruakan media dan pesan budaya bagi anggotanya dan anggota masyarakat yang lain (Husna Fathayatul,2016:28).

Dalam proses penciptaan karya seni seorang seniman selalu berhubungan dengan media yang dipilihnya untuk menghasilkan bentuk tertentu. Pemilihan media ini menentukan apa yang harus dia kerjakan sehingga ide yang dibabarkan tercapai. Perbedaan penggunaan menyebabkan munculnya beberapa jenis seni. Menurut Oswald Kuple mengelompokkan seni dalam beberapa jenis sebagai berikut:

1. Seni yang dinikmati dengan media pendengaran (auditory art), yaitu: Seni musik (dengan nada), seni sastra (dengan kata), dan seni suara (dengan nada dan kata).

2. Seni yang dinikmati dengan media penglihatan (visual art).

3. Seni yang dinikmati dengan media penglihatan dan pendengaran (auditory visual art).

Dalam pelaksanaan festival sudah tentu pihak pelaksana harus mempersiapkan acara ini dengan sebaik mungkin, apalagi pelaksanaannya merupakan festival yang cukup besar dari festival sebelumnya, untuk itu, dalam pelaksanaannya diperlukan persiapan, konsep, perencanaan serta penanganan yang lebih serius atau sungguh-sungguh. Dalam melaksanakan pekerjaan karya seni agar berhasil dengan baik diperlukan perencanaan program kegiatan yaitu: Menyusun jadwal kegiatan penampilan acara (Ario Kartono, 2005:6).

\section{Kaitan Seni dengan Komunikasi}

Berkomunikasi artinya mengadakan interaksi antara dua pihak, sehingga terjadi suatu pengertian timbal balik antara keduanya. Dua pihak tersebut dapat berupa individu dengan individu, individu dengan kelompok, atau kelompok dengan kelompok.

Pada umumnya orang menggunakan bahasa sebagai media komunikasi. Hal ini dapat dimengerti karena bahasa merupakan alat komunikasi yang sederhana dan mudah dimengerti. Namun kenyataannya didunia ini ada banyak bahasa yang tumbuh, yaitu bahasa daerah, bahasa nasional, dan bahasa-bahasa lokal lainnya. Study kebudayaan atau budaya mempelajari music, bahwa seni musik termasuk bagian dari media dan pesan budaya bagi anggotanya maupun anggota masyarakat lain. Sedangkan dalam teori komunikasi kaitan seni termasuk dalam teori informasi yaitu: Sebuah teori pengiriman sinyal. Teori informasi asalnya Claude Shannon, teori informasi digambarkan "mempunayai cakupan (scope) yang cakupan bersifat umum, penangan masalahnya fundamental, capaiannya mempunyai kesederhanaan dan kekuatan klasik".

\section{METODOLOGI PENELITIAN}

Metode yang digunakan dalam penelitian ini, adalah pendekatan analisis kuantitatif data hasil pengukurannya merupakan data kualitatif yang diangkakan atau diskor. Populasi adalah jumlah keseluruhan dari karakteristik atau unit hasil pengukuran dari objek penelitian. Adapun yang menjadi populasi dalam penelitian ini adalah seluruh siswa SMA Negeri 6 mulai dari kelas X s/d kelas XII berjumlah 1201 orang. Dalam penelitian ini tekhnik 
pengambilan sampel dilakukan dengan cara random sampling yaitu cara pengambilan dilakukan secara acak tanpa memperhatikan tingkatan dalam anggota populasi, sampel dalam penelitian ini menggunakan rumus Slovin. Jadi sampel dalam penelitian ini berjumlah 120 orang siswa

Teknik pengumpulan data dalam penelitian ini yaitu: Kuesioner (penulis menyebarkan sejumlah angket kepada siswa yang menjadi responden dalam penelitian ini), Wawacara (wawancara yang sangat mendalam dilakukan kepada narasumber, dalam hal ini yang menjadi narasumber adalah: Kepala Sekolah, Wakil Kepala Sekolah, Guru-guru seni, siswa osis, dan seluruh staf), Dokumentasi (berupa arsip, dan foto-foto yang ada kaitannya dengan penelitian, Studi Pustaka (studi perpustakaan untuk memperoleh informasi melalui teori-teori yang berhubungan dengan penelitian).

Teknik analisa data dalam penelitian ini yaitu: menggunakan teknik analisis data regresi sederhana, Regresi disebut juga dengan "peramalan" adalah suatu proses memperkirakan secara sistematis tentang apa yang paling mungkin terjadi dimasa yang akan datang berdasarkan informasi masa lalu dan sekarang yang dimiliki agar kesalahannya dapat diperkecil. Regresi dapat juga diartikan sebagai usaha memperkirakan perubahan. Supaya tidak salah paham bahwa peramalan tidak memberikan jawaban pasti tentang apa yang akan terjadi, melaikan berusaha mencari pendekatan tentang apa yang akan terjadi (Priyatno Duwi,2012:73).

\section{HASIL DAN PEMBAHASAN}

\section{Hasil Pengujian Data Penelitian (Uji Validitas)}

Uji validitas adalah suatu ukuran yang menunjukkan tingkat kevalidan atau kesahihan suatu instrument. Suatu instrument yang valid mempunyai validitas tinggi dan sebaliknya bila tingkat validitasnya rendah maka instrument tersebut kurang valid. Sebuah instrumen valid apabila mampu mengukur apa yang hendak diukur/diinginkan. Berikut hasil uji validitas dan reliabilitas instrumen penelitian ini:

Tabel 1. Hasil Validitas dan Rehabilitas SPSS

Scale: All Variables, Case Processing Summary

\begin{tabular}{|ll|c|c|}
\hline & & $\mathrm{N}$ & $\%$ \\
\hline Cases & Valid & 10 & 26.3 \\
& Excluded $^{\mathrm{a}}$ & 28 & 73.7 \\
& Total & 38 & 100.0 \\
\hline
\end{tabular}


Tabel 2. Hasil Validitas dan Rehabilitas SPSS

Scale: All Variables

Reliability Statistics

\begin{tabular}{|lcl|c|}
\hline Cronbach's & Part & Value & .878 \\
Alpha & 1 & N of Items & $19^{\mathrm{a}}$ \\
& Part & Value & .873 \\
& 2 & N of Items & $19^{\mathrm{b}}$ \\
& Total N of Items & 38 \\
Correlation Between Forms & .874 \\
Spearman- & Equal Length & .933 \\
Brown & Unequal Length & .933 \\
Coefficient & & .928 \\
Guttman Split-Half Coefficient & \\
\hline
\end{tabular}

a. The items are: no1, no2, no3, no4, no5, no6, no7, no8, no9, no10, no11, no12, no13, no14, no15, no16, no17, no18, no19.

b. The items are: no20, no21, no22, no23, no24, no25, no26, nо27, nо28, nо29, no30, no31, no32, no33, no34, no35, no36, no37, no38.

Hasil Proses memaknai Uji Validitas dan Reliabilitas

Nilai $r_{\text {hitung }}>r_{\text {tabel }}$ Maka item tersebut valid rtabel: $\alpha=$ $0.05 ; \mathrm{n}=10$

\begin{tabular}{lllc}
\hline no1 & 0.702 & $>0.632$ & Valid \\
\hline no2 & 0.522 & $<0.632$ & Tidak valid \\
\hline no3 & 0.700 & $>0.632$ & Valid \\
\hline no4 & 0.638 & $>0.632$ & Valid \\
\hline no5 & 0.744 & $>0.632$ & Valid \\
\hline no6 & 0.647 & $>0.632$ & Valid \\
\hline no7 & 0.389 & $<0.632$ & Tidak valid \\
\hline no8 & 0.755 & $>0.632$ & Valid \\
\hline no9 & 0.543 & $<0.632$ & Tidak valid \\
\hline no10 & 0.679 & $>0.632$ & Valid \\
\hline no11 & 0.687 & $>0.632$ & Valid \\
\hline
\end{tabular}




\begin{tabular}{|c|c|c|c|}
\hline no12 & 0.557 & $<0.632$ & Tidak valid \\
\hline no13 & 0.701 & $>0.632$ & Valid \\
\hline no14 & 0.703 & $>0.632$ & Valid \\
\hline no15 & 0.701 & $>0.632$ & Valid \\
\hline no16 & 0.429 & $<0.632$ & Tidak valid \\
\hline no17 & 0.680 & $>0.632$ & Valid \\
\hline no18 & 0.189 & $<0.632$ & Tidak valid \\
\hline no19 & 0.684 & $>0.632$ & Valid \\
\hline no20 & 0.669 & $>0.632$ & Valid \\
\hline no21 & 0.842 & $>0.632$ & Valid \\
\hline no 22 & 0.670 & $>0.632$ & Valid \\
\hline no23 & 0.359 & $<0.632$ & Tidak valid \\
\hline no24 & 0.700 & $>0.632$ & Valid \\
\hline no25 & 0.409 & $<0.632$ & Tidak valid \\
\hline no26 & 0.645 & $>0.632$ & Valid \\
\hline no27 & 0.734 & $>0.632$ & Valid \\
\hline no28 & 0.720 & $>0.632$ & Valid \\
\hline no29 & 0.335 & $<0.632$ & Tidak valid \\
\hline no30 & 0.671 & $>0.632$ & Vallid \\
\hline no31 & 0.737 & $>0.632$ & Valid \\
\hline no32 & 0.707 & $>0.632$ & Valid \\
\hline no33 & 0.652 & $>0.632$ & Valid \\
\hline no34 & 0.388 & $<0.632$ & Tidak valid \\
\hline no35 & 0.690 & $>0.632$ & Valid \\
\hline no36 & 0.684 & $>0.632$ & Valid \\
\hline no37 & 0.701 & $>0.632$ & Valid \\
\hline no38 & 0.178 & $<0.632$ & Tidak valid \\
\hline
\end{tabular}

Dari tari tabel di atas dapat disimpulkan bahwa, hasil uji validitas instrumen berada pada kategori valid hal ini berdasarkan nilai reliabilitas nilai korelasi Gutman split - Half coefficient $=0.928$ korelasi berada pada kategori sangat kuat.

\section{Bentuk Pelaksanaan Festival Seni di SMAN 6}

Untuk mengetahui bagaimana bentuk pelaksanaan festival seni di SMAN6, maka penulis melakukan wawancara dan menyebarkan sejumlah angket kepada siswa/i, Kepala Sekolah, Wakil Kepala Sekolah bagian kesiswaan, dan guru seni SMA Negeri 6 Pekanbaru. Berdasarkan hasil wawancara dengan didapatkan hasil sebagai berikut: 
Bentuk pelaksanaan festival seni disekolah yaitu Sangat baik apabila berada diantara $76 \%-100 \%$, Cukup baik apabila berada diantara 56\% - 76\%, Kurang baik apabila berada diantara 40\% - 55\%, Tidak baik apabila berada diantara 0\% - 40\%. Jika dilihat dari ukuran diatas, maka dapat diketahui bahwa prosentase rata-rata diatas berada dalam kategori sangat baik karena $94.74 \%$ berada antara $76 \%-100 \%$.

\section{Bentuk Citra Sekolah}

Untuk melihat bagaimana citra sekolah, citra dapat diartikan sebagai persepsi masyarakat terhadap jati diri dari suatu perusahaan. Jika demikian suatu perusahaan harus berupaya sedemikian rupa agar masyarakat luas tidak mempunyai persepsi yang menyimpang (Lawrence L.Steinmetz). Berdasarkan hasil wawancara dengan didapatkan hasil sebagai berikut:

Prosentase rata-rata yang diperoleh diatas merupakan bentuk citra sekolah di SMAN 6 sesuai dengan indicator citra. Untuk menentukan kategori prosentase diatas digunakan ukuran sebagai berikut:

Sangat baik apabila berada diantara 76\% - 100\%, Cukup baik apabila berada diantara 56\% $75 \%$, Kurang baik apabila berada diantara $40 \%-55 \%$, Tidak baik apabila berada diantara $0 \%-40 \%$.

Jika dilihat dari ukuran diatas, maka dapat diketahui bahwa prosentase rata-rata dari ukuran berada dalam kategori sangat baik karena $83.2 \%$ berada antara 70\% - 100\%.Dengan demikian dapat diketahui bahwa bentuk citra sekolah diSMAN6 sangat baik dan positif sehingga mampu memotivasi siswa meraih prestasi dan mewujudkan impiannya.

\section{Pengaruh Acara Festival Seni Terhadap Citra Sekolah}

Untuk melihat pengaruh acara festival seni terhadap citra sekolah penulis menyebarkan sejumlah pertanyaan dalam bentuk angket kepada responden yang menjadi sampel dari penelitian ini dan penulis berharap mudah-mudahan dari sampel bisa mewakili jumlah populasinya.

Dalam penyusunan instrumen penelitian ini penulis menggunakan skala pengukuran yaitu skala likert yang digunakan untuk mengukur sikap, pendapat, dan persepsi seseorang atau sekelompok orang tentang kejadian atau gejala social (Riduwan, 2009: 20).

Berikut analisis peneliti berdasarkan indikator variable penelitian yaitu variable $\mathrm{X}$ Acara festival seni terhadap variable Y Citra Sekolah. Dalam melakukan analisis peneliti menggunakan program SPSS IBM 16. Berikut hasil analisis regesi linier sederhana:

Tabel 3. Regression

\begin{tabular}{cccc}
\hline \multicolumn{4}{c}{ Variables Entered/Removed $^{\mathbf{b}}$} \\
\hline Model & Variables Entered $^{\text {Restival Seni }}{ }^{\mathrm{a}}$ & Variables Removed & Method \\
\hline 1 & Fester & $\cdot$ & Enter \\
\hline
\end{tabular}

Hasil dari table variables entered/removed, bahwa pada bagian ini menjelaskan tentang variable yang dimasukkan adalah festival seni dan tidak ada variable yang dikeluarkan, hal ini dikarenakan metode yang dipakai adalah single step (enter) dan bukan stepwise. 
Tabel 3. Tabel Model Summary

\begin{tabular}{ccccc}
\hline \multicolumn{5}{c}{ Model Summary } \\
\hline Model & $\mathrm{R}$ & R Square & Adjusted R Square & $\begin{array}{c}\text { Std. Error of the } \\
\text { Estimate }\end{array}$ \\
\hline 1 & $.803^{\mathrm{a}}$ & .645 & .642 & 507.650 \\
\hline
\end{tabular}

a. Analisa Tabel Model Summary

Pengaruh Acara festival seni terhadap citra sekolah. Regresi sederhana Acara festival seni (X) Terhadap Citra Sekolah (Y) Pada bagian ini ditampilkan nilai $\mathrm{R}=0.803$ dan koefisien determinasi ( $\mathrm{R}$ Squere) sebesar 0.645 (adalah pengkuadratan dari koefisien korelasi, atau 0.803 X $0.803=0.645)$, Hal ini menunjukkan pengertian bahwa citra sekolah (Y) dipengaruhi sebesar $64.5 \%$ oleh festival seni $(\mathrm{X})$, sedangkan sisanya $(100 \%-64.5 \%=$ $35.5 \%$ ) dijelaskan oleh sebab-sebab yang lain. Rsquere berkisar pada angka 0 sampai 1 , dengan catatan semakin kecil angka RSquere, semakin lemah hubugan antara kedua variable. Dengan demikian dari hasil table model summary bahwa, festival seni (X) berpengaruh terhadap citra sekolah (Y) 64\%, artinya berpengaruh signifikan hal ini disebabkan karena tidak terlepas dari kerja keras pihak sekolah yaitu, Kepala Sekolah, Wakil Kepala Sekolah, Guru Seni, dan Siswa/I OSIS dalam menyukseskan, dan memberikan dukungan sepenuhnya pada kegiatan ini.

b. Tabel Uji Anova

Hasil pengukuran Tabel uji Anova Pada bagian ini ditampilkan hasil yang diperoleh adalah nilai $\mathrm{F}=214.526$ dengan tingkat probabilitas sig. 0.000 oleh karena probabilitas (0.000) jauh lebih kecil dari 0.05 maka model regresi bisa dipakai untuk memprediksi citra sekolah.

Tabel 4. Coefficients

\begin{tabular}{|c|c|c|c|c|c|c|}
\hline & \multirow{2}{*}{ Model } & \multicolumn{2}{|c|}{ Unstandardized Coefficients } & \multirow{2}{*}{$\begin{array}{c}\text { Standardized } \\
\text { Coefficients }\end{array}$} & \multirow{2}{*}{$\mathrm{T}$} & \multirow{2}{*}{ Sig. } \\
\hline & & B & Std. Error & & & \\
\hline \multirow{2}{*}{1} & (Constant) & 27.548 & 4.285 & & 6.430 & .000 \\
\hline & FESTIVAL SENI & .771 & .053 & .803 & 14.647 & .000 \\
\hline
\end{tabular}

c. Tabel Uji Coefficients,

Hasil pengukuran Tabel Uji Coefficients Pada bagian ini dikemukakan nilai konstanta (a) $=27.548$ dan beta $=0.803$ serta harga $t \_$hitung dan tingkat signifikansi $=0.000$ dari table diatas diperoleh persamaan perhitungannya adalah $: \hat{y}=27.548+0.803 X$.

Keterangan: Konstanta sebesar 27.548 menyatakan bahwa jika tidak ada acara festival seni, maka citra sekolah adalah 27.548

Persamaan regresi ( $\hat{y}=27.548+0.803 X$ ) yang didapat tersebut selanjutnya akan diuji apakah memang valid untuk memprediksi variable dependen. Dengan kata lain, akan dilakukan pengujian apakah festival seni benar-benar dapat memprediksi citra sekolah 
dimasa yang akan datang. Disini akan diberi contoh uji koefisien regresi dari variable festival seni.

\section{SIMPULAN}

Berdasarkan temuan yang diperoleh di lapangan, hasil observasi, pengolahan data dan analisis penelitian maka dapat disimpulkan:

1. Bentuk Pelaksanaan Festival Seni.

Bentuk pelaksanaan kegiatan festival seni di SMAN 6 sangat tersusun dan terencana dengan baik, sehingga hal ini menyebabkan SMAN 6 dalam melaksanakan kegiatan selalu berhasil dan mendapat sambutan positif bagi peminatnya.

2. Bentuk Citra Sekolah.

Citra SMAN 6 dimata siswa cukup baik dan sangat sangat positif ditandai dari rekapitulasi jawaban responden yang menjawab sangat setuju tentang kegiatan positif yang dilaksanakan oleh SMAN 6 melalui kegiatan festival seni.

3. Pengaruh Acara Festival Seni Terhadap Citra Sekolah.

Pengaruh acara festival seni terhadp citra SMAN 6 sangat berpengaruh signifikan hal ini dibuktikan dari hasil regresi linier sederhana Ternyata nilai t hitung $>\mathrm{t}$ table, atau 27.548 > 1.980, maka Ho ditolak dan Ha diterima, artinya signifikan.

\section{REFERENSI}

\section{Buku:}

Munir, A. (2012). Membangun Komunikasi Efektif, Yogyakarta: Mentari Pustaka Hubeis, M. (2012). Komunikasi Profesional, Bogor: IPB Press.

Arifin, A. (1994). Strategi Komunikasi, Sebuah Pengantar Ringkas. Bandung: Amrico. Arafat, W. (206). Behind A Powerful Image. Jakarta:PT. Raja Grafindo Persada.

Adriana D., Chandra, G, Tjiptono, F. (2007). Pemasaran Strategik. Yogyakarta: Andi.

Alifahmi, H. (2008). Sinergi Komunikasi Pemasaran,. Bandung: Interaksi Iklan, Public Relations Dan Promosi, Mizan Media Utama,

Cangara, H. (2007). Pengantar Ilmu Komunikasi. Jakarta: PT. Raja Grafindo Persada.

Dwi, P. (2012). Belajar Cepat Olah Data Statistik dengan SPSS. Yogyakarta: Andi.

Emilia, E. (2009). Menulis Tesis Dan Disertasi. Bandung: Cv. Alfabeta.

Hart, A.N., Stapleton, J. (2005). Kamus Marketing. Jakarta: Bumi Aksara.

Kotler, P. (2002). Manajemen Pemasaran, edisi milenium 2. Jakarta: Prenhalindo.

Kartono, A. (2005). Berkreasi Seni. Jakarta: PT Ganeca Exact.

Kriyantono, R. (206). Teknik Praktis Riset Komunikasi. Jakarta: Prenada Media Group.

Kartajaya, H. (2009). Brand Operation. Jakarta: PT Erlangga.

Morrisan. (2008). Manajemen Public Relations Strategi Menjadi Humas Profesional. Jakarta: PT Kencana Prenada Media Group.

Moleong, L. J. (2012). Metodologi Penelitian Kualitatif. Bandung: PT Remadja Rosda Karya.

Nicolino, F. P. (2001). Brand Management. Jakarta: Prenada Media. 
Ruslan, R. (1995). Kiat dan Strategi Kampanye Public Relations Edisi Revisi. Jakarta: PT Raja Grafindo Persada.

Rangkui, F. (2002). Creating Effective Marketing Plan. Jakarta: PT Gramedia Pustaka Utama.

Riduwan, S. (2009), Pengantar Statistika. Bandung: ALFABETA.

Rakhmat, J. (2009). Metode Penelitian Komunikasi. Bandung: PT Remaja Rosda Karya.

Rahman, A. (2010) Marketing Mix. Jakarta: Trans Media Pustaka.

Sumarjo, (2000). Filsafat Seni. Bandung: Penerbit ITB.

Sutinah, B. S. (2005). Metode Penelitian Sosial. Jakarta: Kencana Prenada Media.

Sholehuddin. (2005). Komunikasi Regulasi Penyiaran. Jakarta: UIN Press.

Soleh, S. MS. (2010). Dasar-dasar Publik Relations. Bandung: Remadja Rosda Karya.

Tjiptono, F \& Candra, G. (2005). Service, Quality and Satisfaction. Yogyakarta: Penerbit Andi.

Fandy. (2011). Manajemen \& Strategik Merek. Yogyakarta: Andi.

Werner J, Jiames W. Tankard, Jr. (2007). Teori Komunikasi. Jakarta: Kencana Prenada Media Group.

\section{Jurnal:}

Husna, F. (2016). Event Kesenian Sebagai Komunikasi Dalam Melestarikan Budaya Daerah. Digilib UIN Suska, Yogyakarta. 